\title{
International Recommendations on Calculation of Absorbed Dose in Biota: A Comprehensive Revue
}

\author{
Wagner de S. Pereira1,2, Alphonse Kelecom² \\ ${ }^{1}$ Multidisciplinary Group of Radio Protection (GMR), Serviço de Radioproteção, Unidade de Tratamento de \\ Minério, Indústrias Nucleares do Brasil, Caldas, Brazil \\ ${ }^{2}$ Laboratory of Radiobiology and Radiometry Pedro Lopes dos Santos (LARARA-PLS), Group of Environmental \\ Themes Assessment (GETA), Universidade Federal Fluminense (UFF), Niterói, Brazil \\ Email: pereiraws@gmail.com
}

Received 15 April 2014; revised 12 May 2014; accepted 4 June 2014

Copyright (C) 2014 by authors and Scientific Research Publishing Inc.

This work is licensed under the Creative Commons Attribution International License (CC BY). http://creativecommons.org/licenses/by/4.0/

c) (i) Open Access

\section{Abstract}

Since the early times, radioprotection has been focused on the human being. Currently this approach has changed, being now also necessary to take care of the protection of the environment from unwanted effects of ionizing radiation. To this end, several institutions (UNSCEAR, ICRP, IAEA, DOE, ACRP) and consortia of institutions (FASSET, ERICA) have established procedures in order to protect the biota of such effects. Developed procedures are based on the calculation of the absorbed dose in biota (ICRP, DOE, IAEA), or on environmental risk assessment-ERA (DOE, ACRP, FASSET, ERICA); but even in this latter approach the parameters used are related to the absorbed doses in biota. The calculation of dose is the standard procedure in human radioprotection, and this points such an approach as the most interesting for providing a convergence between human and nonhuman (= biota) radioprotections. On the other hand, the ERA approach is easier to apply, because this methodology is used in several countries for non-radioactive contamination assessments. Since the world radioprotection system follows a number of institutions (UNSCEAR, ICRP, IAEA and regulatory institutions of member countries) that use dose calculation, this appears to be the way for biota radioprotection. We here review and comment the evolution of the concepts and approaches of the recommendations for radioprotection of non-human biota.

\section{Keywords}

Biota, Absorbed Dose, Radioprotection, International Recommendations 


\section{Introduction}

Since its origin, radioprotection is focused on the protection of the human being and aims to restrict exposure of individuals of the public. Similarly, protection of the environment was achieved according to the routes of human exposure to radiation. In fact, the concept of environmental radioprotection of the biota is a new approach that has been developed by the radioprotection community, mainly in the last decade [1]-[4]. The first concepts for environmental radioprotection, proposed in 1977 and modified in 1990, were derived from an anthropocentric point of view by the International Commission of Radiological Protection-ICRP [5] [6] that stated: "The commission therefore believes that if man is adequately protected then other living things are also likely to be sufficiently protected". This vision was justified by the greater radiosensibility of the human species, when compared to other species, as pointed out by some authors [7] [8] and by ICRP itself [5] [6].

However, this approach does not withstand a simple ecological analysis. Indeed, differences in niches between the human species and all other representatives of the biota will necessarily generate different exposures. Type and rates of food consumption (through different food webs), breathing rates, water intake, physiological differences in absorption, biokinetics of elements in the organisms can be cited as fundamental to this assessment.

As expected, the anthropocentric approach was questioned by several authors [7]-[13]. ICRP itself [6] reassessed its own paradigm to state that: "Occasionally, individual members of non-human species might be harmed, but not to the extent of creating imbalance endangering whole species or between species". In addition, there are two other important facts to question the anthropocentric assertion: first, there are ecosystems in which the human being is not present (e.g. the ocean) and second, in emergency situations there is a recommendation to evacuate all humans from the so-called exclusion zones, but this cannot be applied to wild animals (e.g. in the surroundings of the Chernobyl and Fukushima nuclear power plants, after the accidents).

The parameters important for assessing the biological effects of radiation on ecosystems can be divided into three groups. The first group concerns the source of radiation and exposure; the second relates to the biology of the irradiated organism and the third relates to environmental factors. For the first group, the important aspects for the evaluation are the kind of radiation, its magnitude, duration and the exposure rate, together with the spatial distribution of the dose. In relation to the biology of the organism, one must consider the number of chromosomes, the volume of the chromosomes, the duration of the mitotic cycle, the percentage of cells that are dividing, the stage of the cell cycle, the cell or tissue type, the stage of cellular differentiation, the size of the organism, its age, the stage of the growth cycle, the nutritional conditions, the existence of sensitizing or protective substances and the biological species. Among ecological conditions, one can mention: season, temperature, humidity, length of daily brightness, solar irradiation, competition, parasitism, predation and kind of food chain [14]. In cited paper, the authors emphasized that the combination of environmental, chemical, physical and biological variables which cause stress to living organisms, has no measurable threshold [14].

In fact, the richness and complexity of Biodiversity has always been an impediment to develop environmental radioprotection due to the multiplicity of factors to be considered. In order to set up a technically defensible mechanism for the protection of biota against the effects of ionizing radiation, the ICRP has made a series of recommendations. In 2003, a recommendation was published to describe a general frame for the protection of biota [1]. In 2007, ICRP stated the need for an explicit, and not implicit, protection of biota and defined the concept of Reference Animals and Plants (RAP) [2]. Finally, in 2009, it developed the mechanisms for dose calculation [3] and put this proposal in practice releasing transfer factors of 39 radionuclides for the suggested RAP [4].

The present study aims to analyze the global framework of the main proposals for protection of biota from ionizing radiation.

\section{Radioprotection of Biota}

\subsection{The World System of Radioprotection. How It Works}

The world radioprotection system has been elaborated step-by-step, along decades, by a series of institutions. The core of the system is composed of three organizations: the United Nations Scientific Committee on the Effects of Atomic Radiation (UNSCEAR), the ICRP and the International Atomic Energy Agency (IAEA). The UNSCEAR is part of the United Nations (UN) and is responsible for collecting data on the biological effects of radiation. Using these data, the ICRP set up recommendations aiming radioprotection, and gives thus a practical 
character to the knowledge of radiobiology. Finally the IAEA, on the basis of the ICRP recommendations, publishes guidelines and recommends their adoption by the member countries through their own legislation. In addition, several other institutions are invited by these organizations to assist them in the formulation of concepts and values used in radioprotection.

\subsection{The Radioprotection of Biota in the Perspective of UNSCEAR}

With respect to UNSCEAR the first reference to radioprotection of biota appeared its 1996 publication [15], and followed the anthropocentric concept developed by ICRP discussed above [5] [6]. In these studies, the biota was considered as a part of the human trophic chain. This approach now changed as can be observed in Annex E of UNSCEAR's recent publication from 2010 [16], where radioprotection proposals, proper to non-human biota, are finally released.

Following the current consensus, radioprotection of biota, proposed by UNSCEAR, is based on the protection of the biota at a minimum population level organization. The absorbed dose is proposed as the radioprotection parameter, and generic limits are established for terrestrial organisms at $100 \mu \mathrm{Gy} / \mathrm{h}$, and for aquatic organisms at $400 \mu \mathrm{Gy} / \mathrm{h}$. In Annex C of its 1996 publication [15], UNSCEAR mentioned non-targeted and delayed effects of exposure to ionizing radiation. Then, in its 2008 publication [16], it recognized that the effects of ionizing radiation do not express themselves only at population level but also at higher organizational levels (community, structure or ecosystem functions), and focus its concern on mechanisms that may affect these organizational levels such as reproductive success, genetic diversity, and so on.

Finally, the UNSCEAR points key elements of a framework for the assessment of the effects of radiation exposure on non-human biota which can be observed in Table 1.

In the same publication UNSCEAR [16] proposed 12 reference organisms (Table 2), for dose assessments and hence for environmental radioprotection based on the concept of dose.

Dosimetric models are described, as well as their respective conversion factors of concentration of activity in dose rate for a number of radionuclides. Models are proposed to be applied in terrestrial and aquatic environments. This study also described the dispersion models of radionuclides in the environment (terrestrial and aquatic) and suggested generic environmental transfer factors to estimate radionuclide concentrations in the environmental compartments of concern.

The UNSCEAR points to the need for establishment of weighting factors for the different kinds of radiation and for organs/tissues, now repeating for biota radioprotection the evolution steps of the units to measure the dose of radiation in man, that started with the absorbed dose (i.e. the energy deposited by ionizing radiation per unit of mass or volume), then skipped to the dose equivalent (i.e. submitting the absorbed dose to a weighting factor depending on the kind of radiation, $\mathrm{w}_{\mathrm{R}}$ ), and finally to the effective dose (i.e. correcting the dose equiva

Table 1. Key elements of a framework for the assessment of the effects of radiation exposure on non-human biota [16].

\begin{tabular}{|c|c|}
\hline Element & Considerations \\
\hline Exposure of biota & $\begin{array}{l}\text { - Spatial and temporal patterns of radionuclide in environment in material; } \\
\text { - Uptake by organism; } \\
\text { - } \quad \text { Non-uniform distribution within organism. }\end{array}$ \\
\hline Reference biota & $\begin{array}{l}\text { - Not possible to evaluate all biota; } \\
\text { - Need to select reference biota or indicator species appropriate for area of interest and } \\
\text { desirable basis for selection; } \\
\text { - Possible need consider individuals biota per se when species are endangered. }\end{array}$ \\
\hline Dosimetry model for reference biota & $\begin{array}{l}\text { - Absorbed dose (to whole body or to tissue/organ); } \\
\text { - } \quad \text { Geometry corrections; } \\
\text { biota. }\end{array}$ \\
\hline Endpoints in radiological assessment & $\begin{array}{l}\text { - Selection of appropriate population level (deterministic) "umbrella" effects such as } \\
\text { mortality or reproductive capacity and corresponding references doses. }\end{array}$ \\
\hline Effects on biota & $\begin{array}{l}\text { - Connection between radiation effects on "umbrella" endpoint in individual, and consequent } \\
\text { "possible" effects on population; } \\
\text { - Role of background radiation levels; } \\
\text { - Natural population variability. }\end{array}$ \\
\hline
\end{tabular}


Table 2. Reference organisms, following UNSCEAR, 2008 [16].

\begin{tabular}{cc}
\hline Reference organism & Reference biota \\
\hline Earthworm & Soil invertebrate \\
Rat & Burrowing mammal \\
Bee & Above ground invertebrate \\
Wild Grass & Grasses, herbs and crops \\
Pine tree & Tree \\
Deer & Herbivorous mammal \\
Duck & Bird \\
Frog & Amphibian \\
Brown seaweed & Microalgae \\
Trout & Pelagic fish \\
Flat fish & Benthic fish \\
Crab & Crustaceans \\
\hline
\end{tabular}

lent by a weighting factor to take into consideration the different kinds of tissues or organs, $\mathrm{w}_{\mathrm{T}}$ ). Although pointing to the need of these weighting factors, the UNSCEAR did not set their values.

\subsection{The Radioprotection of Biota under the Point of View of ICRP}

The ICRP has several publications related to environmental radioprotection; the most important were the recommendations $\mathrm{N}^{\circ} 26$ released in 1977 [5], $\mathrm{N}^{\circ} 60$ in1990 [6] and $\mathrm{N}^{\circ} 103$ in 2007 [2]. In addition to these, one should mention publications $\mathrm{N}^{\circ} 91$ in 2003 [1] entitled: "A framework for assessing the impact of ionizing radiation on non-human species", $\mathrm{N}^{\circ} 108$ in 2009 [3], entitled: "Environmental Protection: the concept and use of reference animals and plants" and $\mathrm{N}^{\circ} 114$ also in 2009 [4], entitled: "Environmental Protection: Transfer parameters for reference animals and plants". The first three publications $\left(\mathrm{N}^{\circ \mathrm{s}} 26,60\right.$ and 103) are general recommendations, mentioning only superficially the theme of environmental radioprotection, but the other three documents ( $\mathrm{N}^{\circ \mathrm{s}} 91,108$ and 114$)$ are specific to the environmental radioprotection.

\subsubsection{Recommendation Number 26 from ICRP (1977)}

The first attempt at environmental radioprotection based on biota appeared in recommendation $\mathrm{N}^{\circ} 26$ [5]. The anthropocentric vision prevailing at the time created the erroneous paradigm saying that if man is protected, then the biota will be protected as well. Indeed, the ICRP recommendation stated that: "Although the principal objective of radiation protection is the achievement and maintenance of appropriate safe conditions for activities involving human exposure, the level of safety required for the protection of all human individuals is thought likely to be adequate to protect other species, although not necessarily individual members of those species. The Commission therefore believes that if man is adequately protected then other living things are also likely to be sufficiently". This statement was questioned by several authors [7] [8] [10]-[13] [17], including the ICRP itself in its recommendations $\mathrm{N}^{\circ}$ 60, 91, 103, 108 and 114 [1]-[4] [6].

\subsubsection{Recommendation Number 60 from ICRP (1990)}

In its recommendation $\mathrm{N}^{\circ} 60$ released in 1990 [6], the ICRP has put in doubt previous statement, saying that: "The Commission therefore believes that if man is adequately protected then other living things are also likely to be sufficiently", now recognizing that in some cases, individuals of the biota may be put at risk. Thus, the ICRP recognized that: "The Commission believes that the Standards of environmental control needed to protect man to the degree currently thought desirable will ensure that other species are not put at risk. Occasionally, individual members of non-human species might be harmed, but not to the extent of endangering whole species or creating imbalance between species. At the present time, the Commission concerns itself with mankind environment only with regard to the transfer of radionuclides through the environment, since this directly affects the radiological protection of man". Despite the exception of the individual risk, the ICRP system continued based on man and all the procedures still aimed at the protection of a single species: the human being. 


\subsubsection{Recommendation Number 91 from ICRP (2003)}

This recommendation is the first to develop a system of protection giving bases and objectives for a true radioprotection of biota, using scientific and ethical principles [1]. It indicated how to assess the environmental radiological impact in terms of environmental protection and not in terms of the human species, as stated previously. Finally, it indicated the need to create a system of radioprotection integrating the one proposed for the human species with the new concepts for non-human species (biota). The objectives of this recommendation are here transcript:

- Defining how the ICRP can contribute to the attainment of society's goals of environmental protection by developing a protection policy based on scientific and ethical-philosophical principles;

- Suggesting a framework for the assessment of the impact of ionizing radiation in the environment based on science to support requirements for protection of the environment against harmful effects of ionizing radiation; and

- Showing how such a proposal for assessment of impact of ionizing radiation in non-human species can be interfaced with or integrated into an overall system of radiological protection.

This recommendation points scientific evidence for the need of environment protection and how this protection can affect, directly or indirectly, the human health, pointing out the need to complement national laws to protect the environment from unwanted effects of radiation.

The evolution of the concepts of environmental radioprotection is discussed in this recommendation, with emphasis on the various approaches. Briefly and according to ICRP, the step-by-step evolution of environmental radioprotection was as follows:

1. At the beginning, an anthropocentric vision prevailed: being man part of the environment, its protection will result in protection of the other species.

2. Then, calculations were used to demonstrate that the proposed annual dose limit of $1 \mathrm{mSv}$ will ensure that the animals and plants of the human food chain will receive smaller doses and will be protected at population level [5];

3. The use of absorbed dose limit was proposed as a mean of protection of biota [1]-[4];

4. The use of the environmental risk assessment (ERA) was introduced to evaluate the effects of radionuclides on biota, together with the use of dosimetric models to estimate the dose rates that produce no measurable effect on some key organisms of the ecosystem [18]-[23];

5. The use of reference animals and plants (RAP) appeared to define a scope of protection that would accommodate dosimetric models, exposure estimate data and data on the relation exposure-biological effect, that could be used for decision-making in different circumstances of control of practices and intervention [1]-[4];

6. Finally, a system for protection of regional or national biota was defined in a practical way [1] [3] [4].

\subsubsection{Recommendation Number 103 from ICRP (2007)}

Recommendation $\mathrm{N}^{\circ} 103$, published in 2007 [2], does not address directly the protection of biota, but the principles that guide radioprotection. Its main contribution to radioprotection of biota was breaking the anthropocentric paradigm, stating that environmental protection cannot be tied to human protection and that national authorities need to establish mechanisms to ensure this protection, as can be seen in the statement "However, the Commission considers that it is now necessary to provide advice with regard to all exposure situations. It also believes that it is necessary to consider a wider range of environmental situations, irrespective of any human connection with them. The Commission is also aware of the needs of some national authorities to demonstrate, directly and explicitly, that the environment is being protected, even under planned situations".

Another significant event in this recommendation was the definition of reference animals and plants (RAP), as follows: "A Reference Animal or Plant is a hypothetical entity, with the assumed basic biological characteristics of a particular type of animal or plant, as described to the generality of the taxonomic level of family, with defined anatomical, physiological, and life-history properties, that can be used for the purposes of relating exposure to dose, and dose to effects, for that type of living organism."

\subsubsection{Recommendation Number 108 from ICRP (2009)}

Recommendation $\mathrm{N}^{\circ} 108$ from 2009 defines the concepts and use of Reference Animals and Plants [3]. It points out the need for a radioprotection common to humans and environment, explains criteria for the choice of RAP, describes in anatomical, physiological and ecological terms a group of RAP, defines the routes of exposure of 
described RAP, and calculates the conversion factors of concentration of activity into absorbed dose rate by the RAP.

In addition to the information given to calculate the dose, the recommendation collects information on the dose-effect relation in the RAP, evaluates them in terms of derived limits, and proposes a correlation between doses range and possible biological effects. The recommendation also proposes applications and extrapolations, emphasizing the differences in the biology, in exposure situations, in radiation dosimetry and in radiation effects among RAP.

With regard to the criteria for protection of biota, this recommendation uses the supra-population level, worrying about biological diversity and not about the individual itself, as can be seen in the following statements: "Since then, the Commission has published its revised set of recommendations [2], in which it considered it appropriate to broaden it in order to address the protection of the environment directly, and thus to include in its general aims the prevention or reduction of the frequency of deleterious radiation effects in the environment to a level where they would have a negligible impact on the maintenance of biological diversity, the conservation of species, or the health and status of natural habitats, communities, and ecosystems. The Commission also stated that it believed that its approach to environmental protection should be commensurate with the overall level of risk, and thus optimized, and that it should be compatible with other approaches being made to protect the environment."

A questionable concept, from a radiological point of view, is the use of the absorbed dose, which in human radioprotection has been replaced by the equivalent dose and by the effective dose that express better the differences in biological responses due to the different kinds of radiation and due to the different radiosensibilities of organs and tissues. An additional question of ecological meaning is related to the protection of biota at community and ecosystems levels rather than at individual level, as occurs for humans. This point is particularly relevant in the case of endangered species where each individual must be protected.

\subsubsection{Recommendation Number 114 from ICRP (2009)}

In publication $\mathrm{N}^{\circ} 114$ from 2009 [4], the ICRP complements recommendation $\mathrm{N}^{\circ} 108$ [3], actually furnishing environmental transfer models together with transfer parameters for 39 radionuclides, to the set of RAP's described in ICRP-108 [3].

\subsection{The Radioprotection of Biota in the Perspective of the IAEA}

The IAEA is the less advanced international institution in relation to biota radioprotection via dose calculation. There is no specific publication on biota radioprotection. Its main recommendation, BSS-115 [24], does not mention biota radioprotection. Two conferences were organized on the topic of "protection of the environment from the effects of ionizing radiation", one in Australia [17], the other in Stockholm [25], but resulting publications reflect the ideas of the authors and not of the IAEA.

\subsection{The Radioprotection of Biota in the Perspective of the DOE}

The Department of Energy of the United States (DOE) began to work on the formulation of biota radioprotection principles in the nineties of past century. The concept laid on the ecological risk assessment (ERA) and focused at the population level of the organisms using reproduction endpoints. DOE did not use the concept of reference animals and plants (RAP) which was developed after their preliminary studies [18]-[20].

DOE reviewed data on acute and chronic radiation effects from biota exposure and proposed dose rates corresponding to expected safe levels of exposure. Values are of $10 \mathrm{mGy} / \mathrm{d}$ for aquatic animals and for terrestrial and aquatic plants, and of $1 \mathrm{mGy} / \mathrm{d}$ for terrestrial animals. DOE was the first to elaborate a model based on a kinetic-allometric approach.

\subsection{The Radioprotection in the Perspective of the Advisory Committee on Radiological Protection (ACRP)}

The Advisory Committee on Radiological Protection considers, as the DOE does, the use of the ERA and identifies chronic toxicity values (CTV) with estimated non effects values (ENEV), as can be seen in Table 3 [26].

In their opinion, the ultimate goal of ecological protection is to ensure that communities and populations of 
Table 3. Estimated non effects values (ENEV) for organisms choice, following ACRP [26].

\begin{tabular}{cc}
\hline Taxa & ENEV (Gy/y) \\
\hline Fish & 0.2 \\
Benthic fish & 2 \\
Algae & 1 \\
Macrophytes & 1 \\
Mammals & 1 \\
Terrestrial plants & 1 \\
Terrestrial invertebrates & 2 \\
\hline
\end{tabular}

organisms can thrive and that all the component parts will be self-sustaining. The ACRP understands that the radionuclides are distributed unevenly, but as far as calculation is concerned, radionuclide distribution is assumed to be homogeneous.

\subsection{The Radioprotection in the Perspective of the Framework for Assessment of Environmental Impact (FASSET)}

Based on the concept of environmental risk assessment (ERA), the FASSET approach indicates a wide variety of issues relevant to the protection of non-human biota from ionizing radiations. It develops dosimetric models, databases of ionizing radiation effects on non-human biota, environmental transfer factors, and indicates some reference organisms. The endpoints used are the morbidity, mortality, reduction of reproductive success and mutation [23].

Within this program the FASSET radiation date base (FRED) was build up. It is a database on the effects of ionizing radiation on non-human biota used as one of the bases by ICRP for its publication $\mathrm{N}^{\circ} 114$ [4].

\subsection{The Radioprotection in the Perspective of Environmental Risk from Ionizing Contaminants: Assessment and Management (ERICA)}

This project is the successor of the FASSET project [23] and undertook an evaluation of data quality of the FASSET and expanded the FRED. It uses the concept of environmental risk assessment tiered methodology that required values of risk assessment screening dose rates for risk characterization within tiers 1 and 2. Following the recommendation of the European Commission, it estimates the predicted non-effect concentration (PNEC). The endpoints used are mortality, morbidity and reproduction. In the case of chronic exposures, the effect dose rates $\left(\mathrm{EDR}_{10}\right)$, in $\mu \mathrm{Gy} / \mathrm{h}$, were estimated. It is the dose rate with $10 \%$ chance of presenting measurable biological effect. Finally, dose rates were established when no measurable effect is expected to occur, named the "predicted non-effect dose rate" (PNEDR) [21] [22].

\section{Conclusions}

There has been a change in the concept of environmental radioprotection. Formerly anthropocentric, it changed to an environmental radiological impact assessment in which the biota is taken into consideration. The current technical framework points the evaluation of absorbed dose in biota as a technically defensible way. The ICRP has proposed the use of range of doses and their possible biological effects, unlike the concept used in human radioprotection where the concept of dose limit is used. The use of the concept of human reference was incorporated into the model, with the choice of some reference organisms. Another difference between the approaches of human and biota radioprotections is the focus of what to protect: considering human radioprotection the focus is the individual, considering non-human biota protection focus on the populations. Even in the absence of a consensus in how to protect the biota, the ICRP built up, since the year 2000, a framework that was consolidated, step-by-step, and that may now be considered as a viable way, both technically and ethically/morally defensible. It may be considered as a progress in relation to the previous concept.

The environmental radioprotection underwent an evolution from the anthropocentric vision to an expanded scope, such as the evaluation of the food chain in terms of dose. The use of the concept of absorbed dose limit 
has been proposed as well as the application of the concept of environmental risk assessment, followed by the concept of RAP. Finally the ICRP set up a framework of biota protection, based on the concept dose absorbed by RAP that is scientifically, ethically and morally defensible.

The absorbed dose expresses adequately the deposition of energy by radiation in matter, but it is not able to express two important facts recognized by human radioprotection: the different biological effects related to the different kinds of radiation, and the different radiosensibilities of the various organs, tissues and organisms. These facts are taken into account using the equivalent dose (kind of radiation) and effective dose (kind of radiation and tissue radiosensibility). Thus, the establishment of weighting factors for radiation and for tissues, organs and organisms seems to be the future, because it allows the convergence of environmental and human radioprotections, in order to harmonize concepts, creating a single radioprotection as intended by ICRP.

\section{References}

[1] International Commission on Radiological Protection-ICRP (2003) A Framework for Assessing the Impact of Ionizing Radiation on Non-Human Species. Elsevier, New York.

[2] International Commission on Radiological Protection-ICRP (2007) The 2007 Recommendations of the International Commission on Radiological Protection. Elsevier, New York.

[3] International Commission on Radiological Protection-ICRP (2009) Environmental Protection: The Concept and Use of Reference Animals and Plants. Elsevier, New York.

[4] International Commission on Radiological Protection-ICRP (2009) Environmental Protection: Transfer Parameters for Reference A and Plants. Elsevier, New York.

[5] International Commission on Radiological Protection-ICRP (1977) Recommendations of the International Commission on Radiological Protection. Elsevier, New York.

[6] International Commission on Radiological Protection-ICRP (1990) Recommendations of the International Commission on Radiological Protection. Elsevier, New York.

[7] Odum, E.P. (1985) Ecologia. 1. Koogan, Rio de Janeiro. 434.

[8] Odum, E.P. and Barret, G.W. (2007) Fundamentos de Ecologia. Thompson, São Paulo.

[9] International Atomic Energy Agency-IAEA (2000) Ethical Considerations in Protecting the Environment from the Effects of Ionizing Radiations. A Report for Discussion. IAEA, Vienna.

[10] Amiro, B.D. (1997) Radiological Dose Conversion Factor for Generic Non-Human Biota used for Screening Potential Ecological Impacts. Journal of Environmental Radioactivity, 35, 35-51. http://dx.doi.org/10.1016/S0265-931X(96)00028-8

[11] Pentreath, R.J. and Woodhead, D.S. (2001) A System for Protecting the Environment from Ionizing Radiation: Selecting Reference Fauna and Flora, and the Possible Dose Models and Environmental Geometry That Could Be Applied to Them. The Science of the Total Environment, 277, 33-43. http://dx.doi.org/10.1016/S0048-9697(01)00888-9

[12] Pentreath, R.J. (2002) Radiation Protection of People and Environment Developing a Common Approach. Journal of Radiological Protection, 22, 1-12. http://dx.doi.org/10.1088/0952-4746/22/1/304

[13] Woodhead, D.S. (1979) Methods of Dosimetry for Aquatic Organisms. Methodology for Assessing Impacts of Radioactivity in Aquatic Ecosystems, IAEA Technical Report 190, 43-96.

[14] Whicker, F.W. and Shultz, V. (1982) Radioecology: Nuclear Energy and the Environment. CRC Press, Boca Raton.

[15] United Nations-UN (1996) Sources and Effects of Ionizing Radiation. United Nations Scientific Committee on the Atomic Radiation. Report to the General Assembly, with Scientific Annex. Annex Part III, New York, 44-86.

[16] United Nations-UN (2008) Sources and Effects of Ionizing Radiation. United Nations Scientific Committee on the Atomic Radiation. Report to the General Assembly, with Scientific Annex, Annex E, Effects of Ionizing Radiation on Non-Human Biota, New York, 221-313.

[17] International Atomic Energy Agency-IAEA (2002) Protection of the Environment from Ionizing Radiation. The Development and Application of a System of Radiation Protection for the Environment, Darwin, 22-26 July 2002, 433.

[18] Department of Energy-DOE (2002) A Graded Approach for Evaluating Radiation Dose to Aquatic and Terrestrial Biota. Module 1: Principles and Application. Oak Ridge, Tennessee, 88.

[19] Department of Energy-DOE (2002) A Graded Approach for Evaluating Radiation Dose to Aquatic and Terrestrial Biota. Module 2: Detailed Guidance. Oak Ridge, Tennessee, 84.

[20] Department of Energy-DOE (2002) A Graded Approach for Evaluating Radiation Dose to Aquatic and Terrestrial Biota. Module 3: Methods Derivation. Oak Ridge, Tennessee, 68. 
[21] Zinger, I., Copplestone, D. and Howard, B.J. (2008) Decision-Making in Environmental Radiation Protection: Using the ERICA Integrated Approach. Journal of Environmental Radioactivity, 99, 1510-1518. http://dx.doi.org/10.1016/j.jenvrad.2008.01.021

[22] Brown, J.E., Alfonso, B., Avila, R., Beresford, N.A., Copplestone, D., Pröhl, G. and Ulanovsky, A. (2008) The ERICA Tool. Journal of Environmental Radioactivity, 99, 1371-1383. http://dx.doi.org/10.1016/j.jenvrad.2008.01.008

[23] Copplestone, D., Hingston, J. and Real, A. (2008) The Development and Purpose of the Frederica Radiation Effects Database. Journal of Environmental Radioactivity, 99, 1456-1463. http://dx.doi.org/10.1016/j.jenvrad.2008.01.006

[24] International Atomic Energy Agency_IAEA (1996) International Basic Safety Standards for Protection against Ionizing Radiation and for the Safety of Radiation Sources-Safety Series 115. IAEA, Vienna, 278.

[25] International Atomic Energy Agency-IAEA (2003) Protection of the Environment from the Effects of Ionizing Radiation. Stockholm, 6-10 October 2003, 561.

[26] Advisory Committee on Radiological Protection-ACRP (2002) Protection of Non-Human Biota from Ionizing Radiation. Canadian Nuclear Safety Commission, info-0703. 
Scientific Research Publishing (SCIRP) is one of the largest Open Access journal publishers. It is currently publishing more than 200 open access, online, peer-reviewed journals covering a wide range of academic disciplines. SCIRP serves the worldwide academic communities and contributes to the progress and application of science with its publication.

Other selected journals from SCIRP are listed as below. Submit your manuscript to us via either submit@scirp.org or Online Submission Portal.
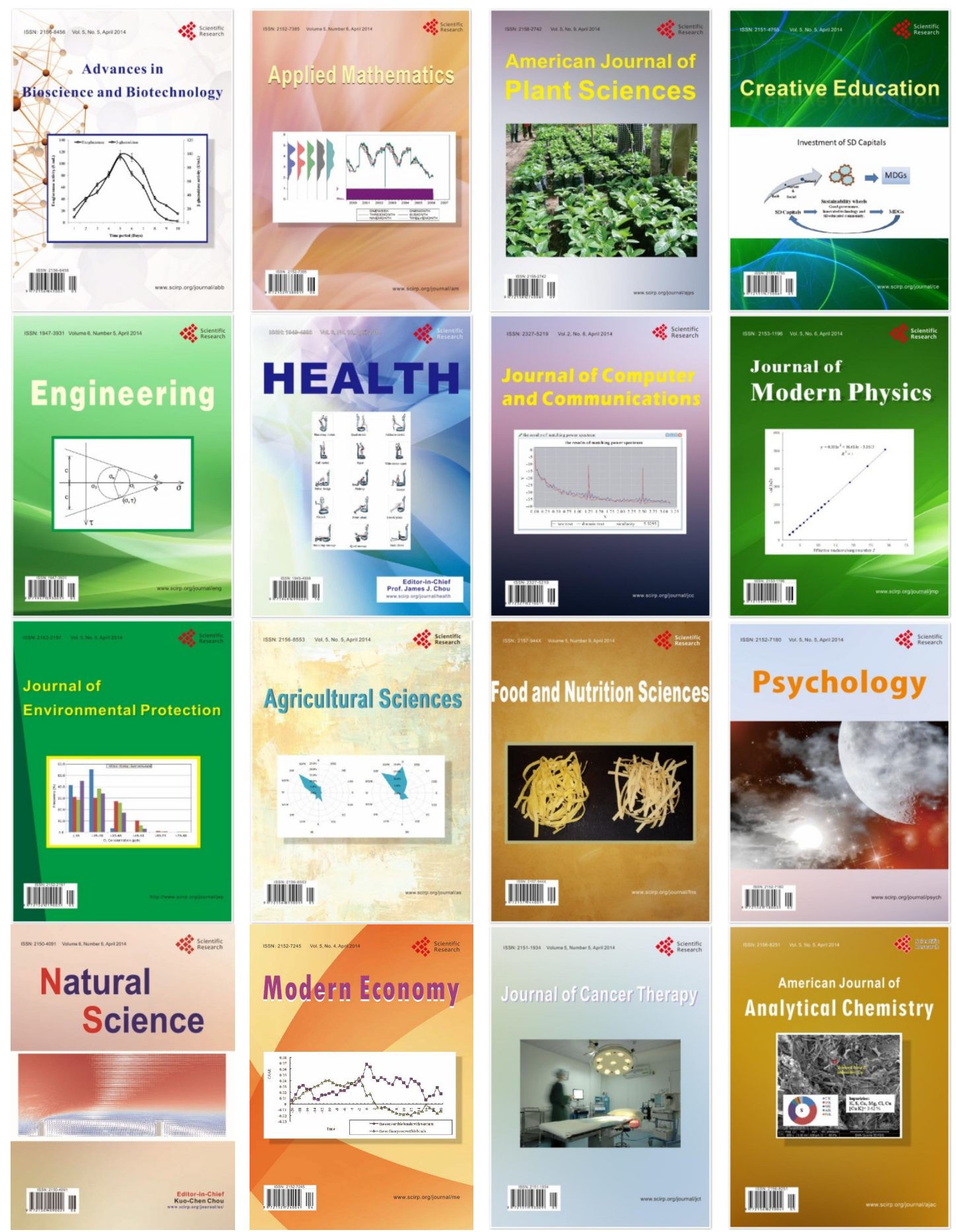